\title{
Development of Multi-Disciplinary Green-BOM to Maintain Sustainability in Reconfigurable Manufacturing Systems
}

\author{
Kezia Amanda Kurniadi and Kwangyeol Ryu *(D) \\ Department of Industrial Engineering, Pusan National University, Busan 46241, Korea; akkez@pusan.ac.kr \\ * Correspondence: kyryu@pusan.ac.kr; Tel.: +82-51-510-3491
}

check for

updates

Citation: Kurniadi, K.A.; Ryu, K. Development of Multi-Disciplinary Green-BOM to Maintain

Sustainability in Reconfigurable

Manufacturing Systems. Sustainability 2021, 13, 9533. https://doi.org/ $10.3390 /$ su13179533

Academic Editors: Adriana Giret, Olivier Cardin and

Damien Trentesaux

Received: 15 July 2021

Accepted: 18 August 2021

Published: 24 August 2021

Publisher's Note: MDPI stays neutral with regard to jurisdictional claims in published maps and institutional affiliations.

Copyright: (c) 2021 by the authors. Licensee MDPI, Basel, Switzerland. This article is an open access article distributed under the terms and conditions of the Creative Commons Attribution (CC BY) license (https:/ / creativecommons.org/licenses/by/ $4.0 /)$.

\begin{abstract}
The reconfigurable manufacturing system (RMS) appears to be eco-friendly while coping with rapidly changing market demands. However, there remains a lack of discussion or research regarding sustainability or environment-friendly functions within RMS. In this study, the reconfiguration planning problem is introduced to represent the core issues within the RMS. Reconfiguration occurs depending on new demands or conditions in the company by reconfiguring machines, such as removing, adding, or changing parts, giving considerable consideration to arrangement of machines, known as configurations in RMS. Therefore, reconfiguration process is always strongly connected to cost, energy consumption, and, more importantly, data management. The complexity of reconfiguration, product variation, and development processes requires tools that are capable of managing multi-disciplinary bill-of-material(BOM) or product data and providing a better collaboration support for data/information tracking while maintaining sustainability. This paper proposes a multi-disciplinary green bill-of-material (MDG-BOM) —an improved Green-BOM concept—with an additional multi-disciplinary feature to minimize emissions and hazardous materials during product development, as well as manage product information across multiple disciplines during the reconfiguration process. A smart spreadsheet for managing MDG-BOM was developed to allow multiple departments to integrate multiple sources of CAD design data and monitor/track changes throughout each step of the process.
\end{abstract}

Keywords: reconfigurable manufacturing systems; reconfigurable planning problem; green bill-of-material; sustainable manufacturing

\section{Introduction}

Recently, the rapid growth of manufacturing systems has mostly been driven by aggressive global competition, smart and demanding consumers, quick innovations of product variation and industrialization [1]. Some long-established manufacturing systems are not suitable for overcoming such new competitive environment. Reconfigurable manufacturing systems (RMS) were developed to become a competitive solution in manufacturing environments and can comply with any changes of demand through systems. RMS performs by altering its capacity to satisfy customer's requirements from time to time. RMS is composed of its dedicated characteristics [2], with the purpose of minimizing reconfiguration cost, time, and effort required, which have become crucial issues [3]. Among those six characteristics, modularity, integrability, and diagnosability are essential characteristics that allow rapid reconfiguration.

In addition, sustainability has become a critical factor that connects product design and manufacturing processes, focusing on minimizing negative environmental impacts and potential harm to the environment and people (such as $\mathrm{CO}_{2}$ and $\mathrm{CH}_{4}$ ) [4]. The concept of sustainability encompasses the economy, environment, and society [4]. Hence, a sustainable manufacturing system extends the role of all of an organization's functional areas into not only pursuing the desired level of economic performance, but also reducing and eliminating any negative environmental impact [5]. Maintaining sustainability in a 
manufacturing system requires a proper framework for developing and producing ecofriendly products. Ryu [5] proposed a novel Bill of Materials (BOM) which is called a Green Bill of Material (Green-BOM). The parts of Green-BOM must have causal relationship with sustainability and technical requirements for more sustainable product designs will be discovered as a result [6-10].

Therefore, this paper aims to discuss the need for studies on reconfiguration planning, which has become a problem within RMS. However, with the complexity of the reconfiguration process regarding product variations and rapid development, it is crucial to develop tools that are capable of managing multi-disciplinary product data and support improved collaboration for data tracking between engineers, while maintaining sustainability. This paper proposes a multi-disciplinary green bill of material (MDG-BOM), which is an open BOM concept based on Green-BOM, with an additional multi-disciplinary feature to minimize emissions and hazardous materials during product development and manage product information across multiple disciplines during the reconfiguration process. Green-BOM is applied in this paper as an additional environmentally friendly function for the system for continuous improvement of the system's sustainability and responsiveness. Green-BOM will be integrated into the BOM formation of part families within the RMS to improve the eco-friendliness of RMS. A case study is delivered for giving a clear description of the process of forming part families for RMS by applying features of Green-BOM.

The complexity of reconfiguration, product variation, and development processes necessitate the use of tools that are capable of handling multi-disciplinary product data and support better collaboration for data tracking between engineers, while maintaining sustainability. This paper proposes an improved concept of Green-BOM, referred to as a multidisciplinary green bill-of-material (MDG-BOM), that has an additional multi-disciplinary feature to minimize emissions and hazardous materials during product development and manage product information across multiple disciplines during reconfiguration. A smart spreadsheet for managing MDG-BOM is developed to provide the means to integrate multiple sources of Computer Aided Design (CAD) data, and monitor and track changes.

\section{Literature Review}

\subsection{Reconfigurable Manufacturing System (RMS) and Reconfiguration Planning Problem (RPP)}

The changeability of manufacturing system caused by rapidly changing market demands and product variations appears as competitive values for global companies. In order to efficiently and effectively leverage changeability, manufacturers need to comprehensively plan and implement the required reconfigurations. Especially in RMS, such a reconfiguration planning problem requires deep understanding of type of product, its characteristics, manufacturing resources, and processes, and other relevant influencing factors that result in reconfigurations. Such planning activities must be conducted continuously, and the product life cycles must be highly considered during reconfiguration planning.

Only a limited number of studies have addressed the efficient and effective leveraging of changeability. Azab et al. [11] used the concept of control analogy to reconfigure manufacturing system and developed its dedicated framework. Other studies mainly discuss changeability in factory-level production structures [12], while changeability of manufacturing inputs at a separate factory level have hardly ever been studied $[8,10]$. Utilizing reconfiguration to improve companies' changeability has only been conducted by modifying the related structures of relevant manufacturing resources [13]. An approach of dedicated and continuous planning for reconfiguration as an important part of RMS implementation is not currently available. Furthermore, the integration of Green-BOM as a part of planning in a factory operation, has not been considered.

The changes of part families in RMS are a crucial part of reconfiguration planning, since it is strongly related to changing conditions by reconfiguring parts, such as adding, removing, changing, and adjusting parts. A framework to represent the structure and state of RMS is necessary to plan what kind of technology and logic we need to reconfigure RMS. The proposed reconfiguration planning framework includes the relevant data on 
the system's structure and environment's state. In the case of RMS, the environment is represented as an arrangement of machines, known as configurations in RMS [12]. The framework involves three main sections, namely, "options", "components", and "documents". Figure 1 shows the relationship between the aforementioned attributes. As shown in Figure 1, "options" is represented as formations, "components" is represented as product families, "documents" is represented as Green-BOM, and "environments" is considered to be an RMS configuration [12].

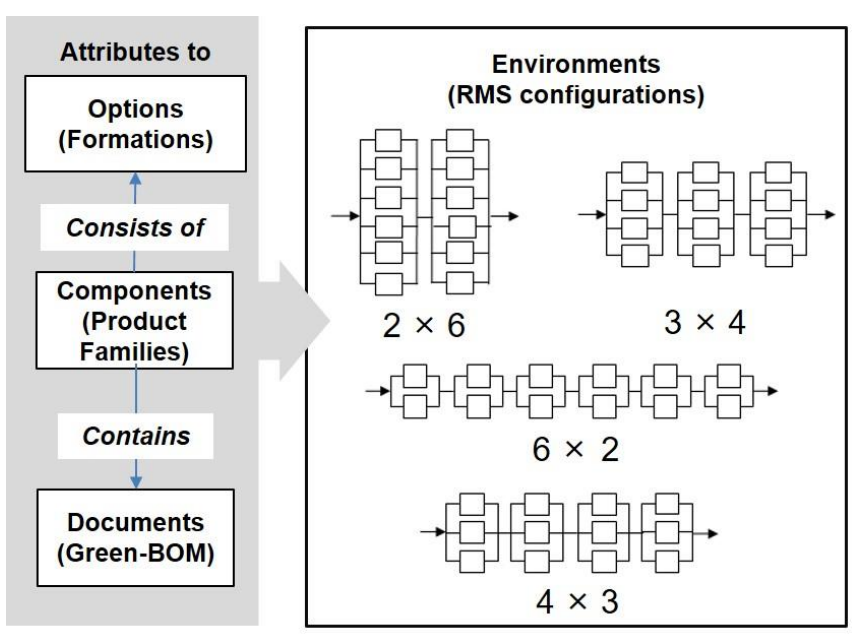

Figure 1. Representation of reconfiguration planning of product family formation in RMS.

A product is composed of combinations of different parts, where each combination of parts serves the desired functions of a complete product. The parts can be represented as "options" and create different product families through the "consists of" relationship. In product modularization, the key factor is the identification of proper functional modules and standardization of different modules. Figure 1 should provide enough support for organizations to manage both green or normal product data simultaneously. In this study, an arrangement or connections of machines or modules is referred to as "reconfiguration". This paper proposed an approach where a configuration is reduced into part families, which is a hierarchy of small parts from the whole system.

The reconfiguration planning framework of forming the part families represented in Green-BOM is shown in Figure 2. Firstly, each type of product is transformed into the format of Green-BOM so that not only the required parts can be determined, but also the relevant attributes of Green-BOM of the product can be monitored. As shown in Figure 2, the modularity/similarity and eco-friendliness between the assumed five types of part (parts 1, 2, 3, 4, and 5) that build products A, B and C, are to be calculated. Then, the part family can be grouped after calculating the value of modularity/similarity between parts and products, as well as their eco-friendliness.

\subsection{Overview of Sustainable Manufacturing}

Sustainable manufacturing can be regarded as a more comprehensive concept of manufacturing system than typical known eco-friendly or green manufacturing systems. Sustainable manufacturing copes with three pillars of sustainability including environment, society, and economy. Sustainability components need to be managed and measured to create a baseline for assessing business performance and improving business processes. There are some available metrics, standards, and frameworks defined for green technologies and sustainable manufacturing [13-18]. 


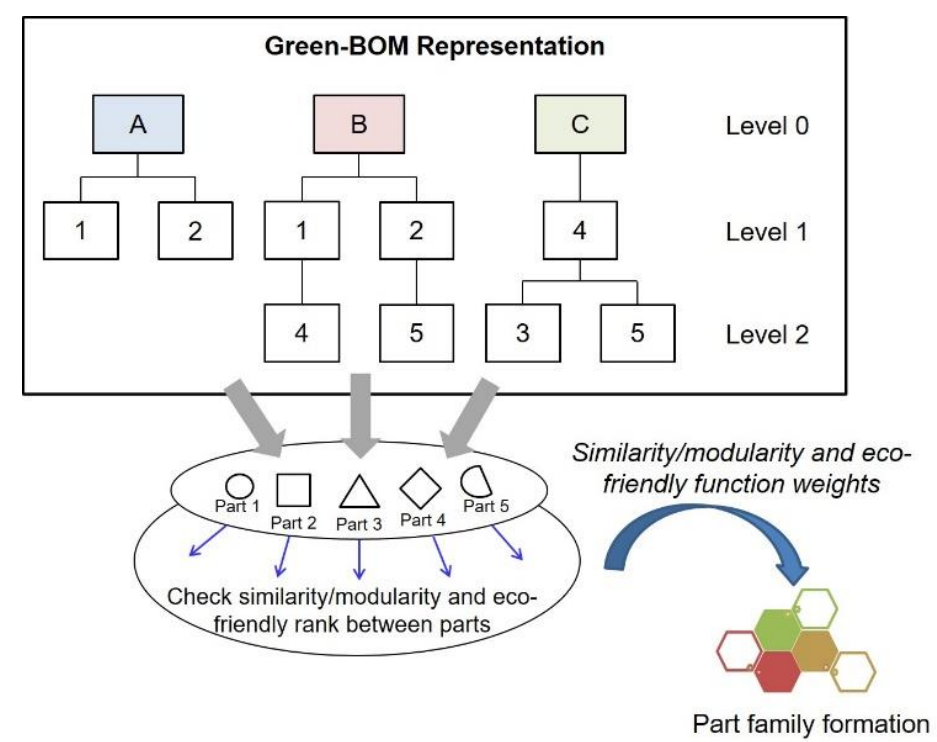

Figure 2. Framework of forming part family represented in Green-BOM.

The sustainability index of an organization is composed of its environmental, economic, and social performance. Certain issues arise from these components. Several aspects of the manufacturing process have positive or negative impacts on each sustainability dimension. Therefore, environmental components are interrelated with resource productivity, climate change, and by-product areas. Manufacturers are able to increase profit, revenue, public opinion, brand image, and longevity by maintaining their financial performance. As a part of social responsibility, manufacturers also share the benefits of sustainability with suppliers/OEMs, such as welfare, updated skills, education, stability, and technology development. Negative environmental impacts are included into a company's cost calculation [3]. By running its operation and adopting the principles of sustainable manufacturing, a company can receive many advantages and improve their business opportunities while avoiding or mitigating possible future threats.

Sustainable manufacturing has been a popular research issue that uses economic and society components together to measure and evaluate some standards in a company. Wang et al. [19] proposed an efficient design for disassembly (DFD) techniques by using an eight-criterion evaluation system of schemes based on sustainability. The result shows that the proposed technique was able to select the best design schemes that satisfies all determined criterions. Tian et al. [20] proposed a hybrid multi-criteria decision-making (MCDM) approach by applying weight vectors based on interior environmental characteristics in order to select the optimal green decoration material. Tian et al. [21] also proposed a methodology to determine the weights of criteria and evaluate the automotive components remanufacturing (ACR) production operation patterns in order to reduce resources-waste and mitigate energy crises.

There has been continuous demand for achieving a desired level of sustainability for global manufacturers. In this regard, Industry 4.0 can be used as a supporting tool that will be very helpful to satisfy such demand [22-24]. There have been collections of studies [25-29] conducted that discuss the link and relationship between sustainability and Industry 4.0. Green-BOM is also one of the credible tools used to help enhance the sustainability value for global manufacturers, which will be further discussed below.

\subsection{Green Bill-of-Materials (Green-BOM)}

As environmental regulations required to make and export products are becoming stronger, components or attributes comprising a BOM, including its structure, should be modified accordingly. Therefore, the structure of a Green-BOM was proposed based on three main phases of a product lifecycle [5]. To make environment-friendly products, 
crucial data or information regarding green product and production should be coherently managed during the whole product lifecycle.

Green-BOM was developed as a new type of BOM, which does not only implicate the definition of an existing BOM but also includes several factors affecting the environment and human health, and its structure is similar to the existing standard BOM [5]. After investigating the existing and popular environmental directives and regulations, six factors of Green-BOM are illustrated in Figure 3.

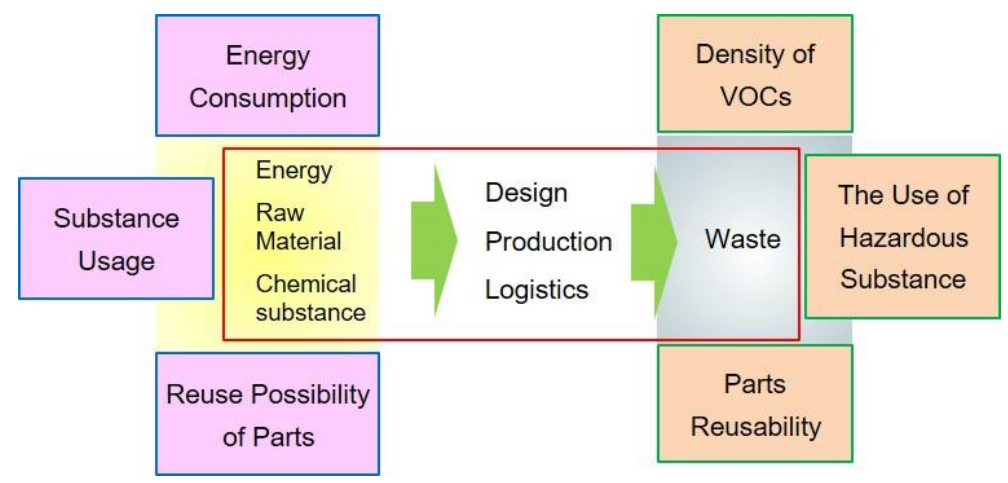

Figure 3. Six factors of Green-BOM [5].

In order to support the implementation of the principle of sustainable manufacturing, a Green-BOM is developed and made suitable for application. Manufacturers adopt the concept of Green-BOM to stay focus and aware on the negative impacts to environment. To produce eco-friendly products, managing product environmental data is crucial. Furthermore, in RMS, the manufacturing system is supposed to be rapidly reconfigured to satisfy new demands, which includes environmental aspects. Figure 4 illustrates normal $\mathrm{BOM}$ and Green-BOM version of a hair dryer.
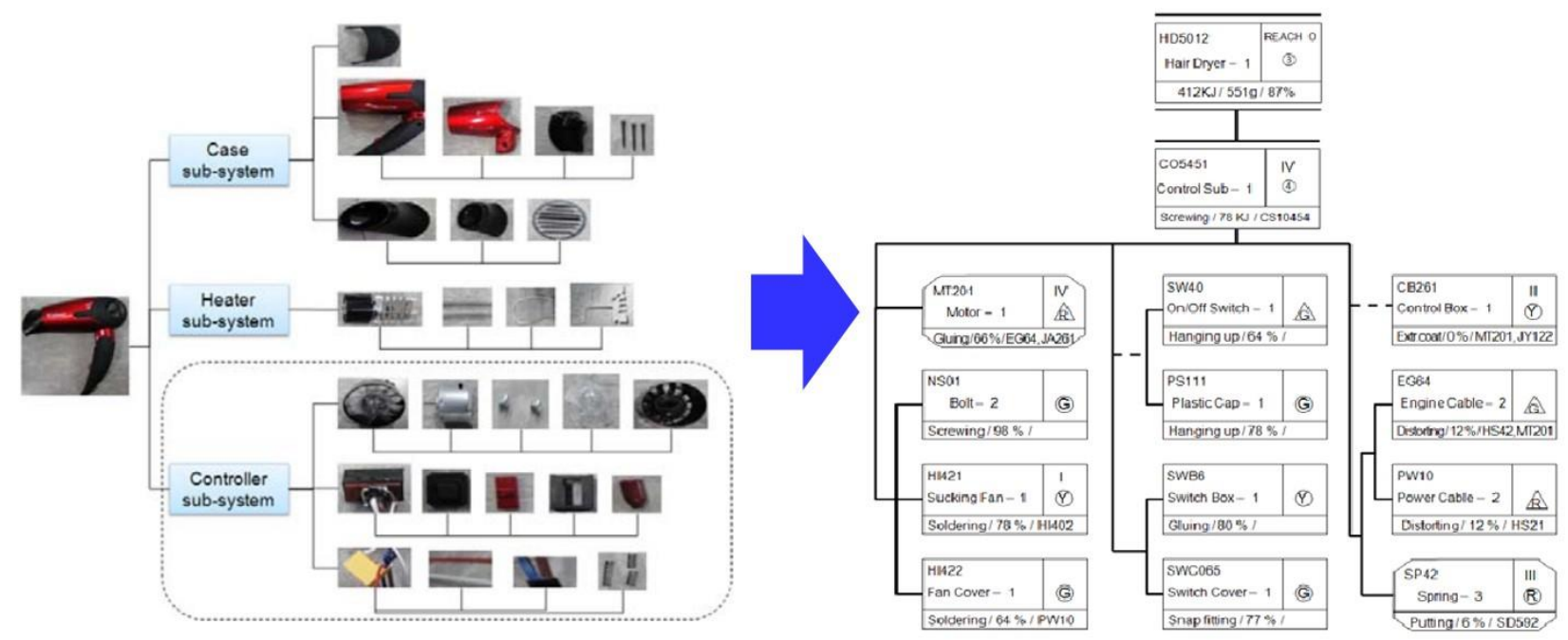

Figure 4. Exemplary normal BOM of a hair dryer and Green-BOM version of it [5].

Hazardous substances restricted by Restriction of Hazardous Substances (RoHS) and Registration, Evaluation, Authorization, and Restrictions of Chemicals (REACH) are removed or minimized during the entire lifecycle. By registering information on hazardous substances that may be contained in parts, the Green-BOM may give awareness to operators to substitute or replace the dangerous parts with safer alternatives. During the product lifecycle, environmental emissions including substance exploitation may cause negative environmental impacts, such as global warming due to $\mathrm{CO}_{2}$ emissions. Therefore, consid- 
ering VOCs and analyzing their effects are crucial to build the functional Green-BOM [5]. Volatile organic compounds (VOCs) are compounds that contains a high vapor pressure that may have terrible impacts to environment and human health. VOC concentrations are usually low, and although the symptoms are slow to develop, VOCs have chronic effects [5]. Table 1 presents the factors, attributes, and descriptions of the Green-BOM factors. Hence, the entire life cycle must be considered. In this study, the Green-BOM was applied during production planning. Therefore, the parts and part families are already eco-friendly when production starts.

Table 1. Factors, attributes and description of Green-BOM factors [5].

\begin{tabular}{|c|c|c|}
\hline Factor & Attributes & Description \\
\hline \multirow{4}{*}{ The Use of Hazardous Substance } & M_toxic & $\begin{array}{l}\mathrm{O}=\text { There is a use of hazardous material } \\
\mathrm{X}=\text { There is no use of hazardous material }\end{array}$ \\
\hline & M_Name & Names of hazardous materials used in parts \\
\hline & M_Guide & Number of hazardous materials \\
\hline & M_Name_Rep & Name of replaceable material \\
\hline \multirow{4}{*}{ Density of VOCs $\left(\mathrm{mg} / \mathrm{m}^{3}\right)$} & $<0.3$ & No relation to human health \\
\hline & $0.3-3.0$ & Possibly affects human health \\
\hline & $>3.0-25$ & Affects human health \\
\hline & $>25$ & Severely affects human health \\
\hline \multirow{2}{*}{ The Use of Substance } & R_Usage & Number of uses of resources used \\
\hline & R_Reused & Number of reused resources compared to total substances \\
\hline \multirow{3}{*}{ Reuse Possibility of Parts } & R_pos & $1=$ possible to reuse parts $0=$ impossible to reuse parts \\
\hline & R_sub & Percentage of reusable materials \\
\hline & R_TR & Number of reusable parts \\
\hline \multirow{2}{*}{ Energy Consumption } & E_M & Consumed by manufacturers \\
\hline & E_C & Consumed by customers \\
\hline \multirow{2}{*}{ Parts Reusability } & N_Ids & Adjacent parts \\
\hline & J/F_type & Assembly method used \\
\hline
\end{tabular}

\subsection{Multi-Disciplinary BOM}

The production engineering projects are typically multidisciplinary and interorganizational [30]. Multi-Disciplinary means combining or involving more than one discipline or field of study. Wang et al. [31] developed an Uncertainty-based Multi-Disciplinary Design Optimization (UMDO) method to analyze the conceptual design of powered Launch Vehicles (LV). Zhang and Huang [32] proposed formulations of Mixed Variables Multidisciplinary Design Optimization (MVMDO) and its dedicated framework to enable designers in solving MDO problems.

The multi-disciplinary concept can also be applied to product management such as $\mathrm{BOM}$ since there are many departments involved in managing $\mathrm{BOM}$ in the real production environment. Therefore, Multi-Disciplinary BOM means a BOM that is able to be managed by more than one department in a company and a BOM that allows for neutral and flexible collaborative data management from multiple personnel. The development of such a BOM is suitable for an RMS environment where the system performs reconfiguration processes and mass customization constantly.

Mass customization means that the demand for each product is likely unique, driven by customer requirements. Regardless of whether the companies are producing or using standardized machines, companies need to create and manage the serial-number-specific $\mathrm{BOM}$ that is able to digitally trace the part development stage through manufacturing and into service life. Such a production system needs to provide greater flexibility to respond to customer demand for customization, especially in RMS.

The management of $\mathrm{BOM}$ is crucial in such a manufacturing environment, especially for the reconfiguration process in RMS, which requires integrated part/product 
management tools. Many companies are managing multiple BOMs that are handled by more than one department. This situation creates many errors and misunderstandings between departments. Figure 5 shows how the complexity of BOM is driven by multiple attributes, such as change management, disciplines, CAD/other content creation tools, and product lifecycle.

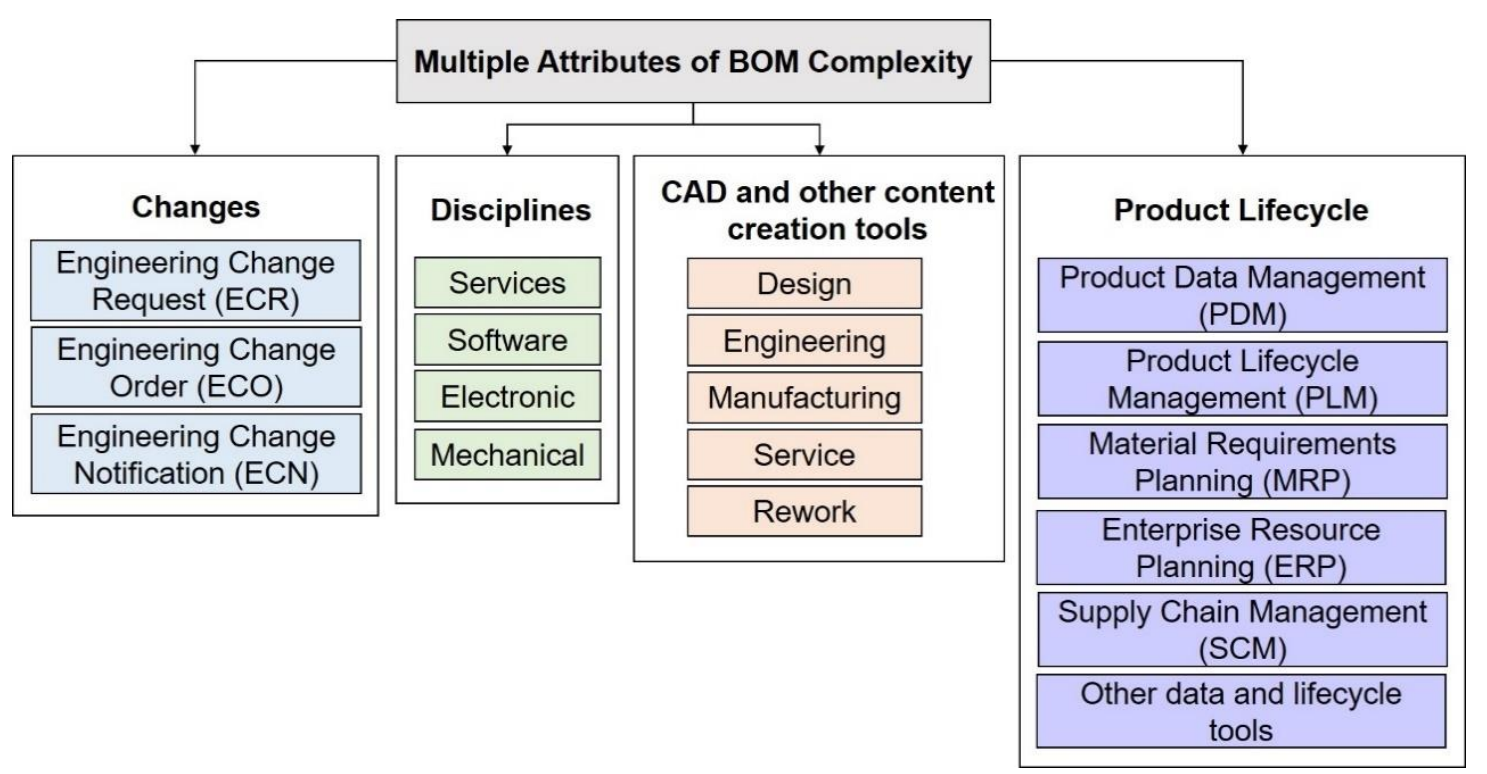

Figure 5. Multiple attributes of BOM complexity.

In Figure 5, BOMs change by integrating three types of displayed changes, such as Engineering Change Request (ECR), Engineering Change Order (ECO), and Engineering Change Notification (ECN). An ECR is created to examine the necessity and feasibility of the change, to identify parts, components, and documentation that might be affected, to estimate costs, and to list the resources required to implement the change. Once the ECR is approved, an ECO is generated, which lists the items, assemblies, and documentation being changed, and includes any updated drawings, CAD files, standard operating procedures (SOPs), or manufacturing work instructions (MWIs) required to make a decision about the change. Once the ECO has been approved, an ECN is sent to affected individuals to let them know that the ECO has been approved and the change should now be implemented.

The aforementioned changes often cause communication errors and failures not only internally among departments in a company, but can also sometimes create problems externally between the company and suppliers or OEMs. All events that generate such changes must be informed simultaneously throughout different stages of product development and related department/operators that focus on the design, manufacturing, and services.

The product complexity involves an unlimited amount of multiple disciplines and departments. Even for a very simple product, the information regarding the structure, design, and characteristics of the products must be spread out through limitless operators, including design, electronic, mechanical, software, assembly, packaging, services, delivery, and many more. The challenge is that every department does not cope with the same area of issues. Furthermore, each engineer uses different tools and has their own designated purpose. Therefore, combining all information for every personnel becomes a very difficult task.

In the product lifecycle, the design of a product represents more than one phase of developing a product, which must go through many operation areas, such as manufacturing, shipping, reworking, remanufacturing, and destroying. All these processes are performed in parallel and require proper interconnections between data and operations. The challenge is the requirement to connect data and information through the process of designing, planning, and optimizing manufacturing and running support services. 
BOM management is considered as one of the most complicated areas in product design and production. In the past, companies managed their product's BOM manually by writing everything on the bulletin board over the factory table. However, these days, such management strategies are not a suitable option anymore. In the future, BOM management systems have to be improved and a proper tool is necessary to manage more complex and dimensional BOM.

There is a requirement for an integrated tool, and as of today, the available tools are not adequately efficient for managing one or multiple BOMs that contain mechanical, electronic and software pieces. The technical differences, complexities, and disagreements between departments can cause trouble for achieving solutions for a cohesive BOM management. There is a necessity to create tools that are capable of managing multi-disciplinary product data that are able to facilitate better collaboration and integrated data/information tracking between departments.

\section{Development of Multi-Disciplinary Green-BOM (MDG-BOM)}

\subsection{Maintaining Sustainability for Forming Product Family in RMS}

Among characteristics of RMS, modularity is considered as an essential one for accomplishing complex and customized products. In general, modularity can be regarded as the level of how a product can be decomposed into several independent parts or modules [33]. Modularity allows for the assembly of customized products because of its concept of simply modular and functionally independent parts [34]. Due to its simplicity of parts, modularity has advantages of decreased total machine operation time and cost [35]. Modularity is also useful as a method for arranging complicated parts, products, and operations [36].

The modularity of a product can be obtained from normal BOM or Green-BOM in this study, which displays the multiple levels of parts and subassemblies that are used in the manufacturing of the product. The left part of Figure 6 displays the structure of product A, which consists of two subassemblies, sub-assembly (SA) \#1 and \#2, and two parts, including Parts $X$ and Y. On the right side of Figure 6, an example in which modularity from a certain variant of products is represented by a BOM.
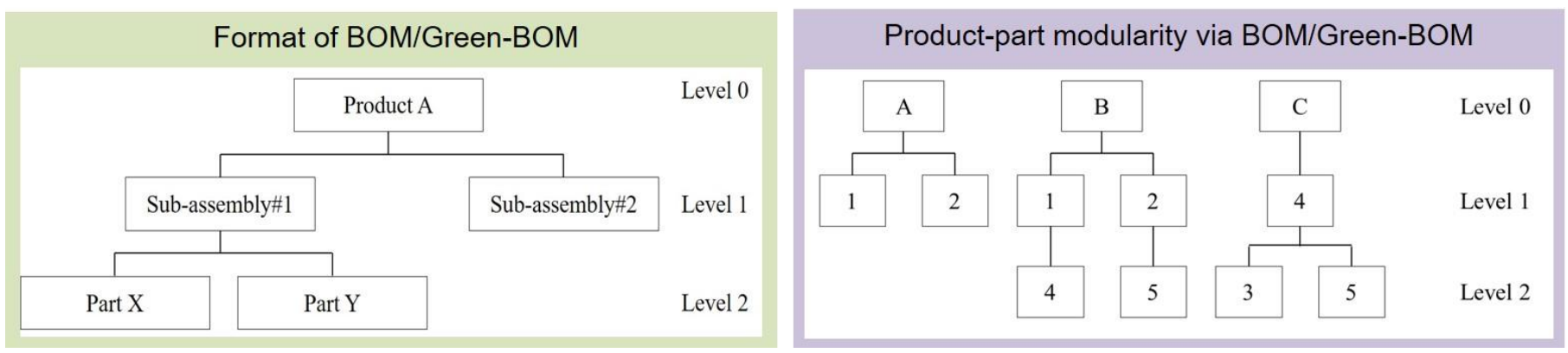

Figure 6. Format of BOM/Green BOM and product-part modularity via BOM/Green-BOM.

A higher modularity rank of a product indicates that it is highly modular. In this way, the manufacturing system can reduce the cost of producing parts and components owing to fewer part variations on one manufacturing floor. In addition to modularity, similarity is also another essential factor to measure the similarity between products from the same family. The similarity can be measured from the view of same manufacturing operations of parts or the same market target of parts.

The modularity rank of a product can be calculated by measuring the number of same parts that are shared by more than one product. For example, in Figure 6, we can see that there are three products, i.e., products A, B and C. Each product has a BOM structure. Product A and B require parts 1, 2, parts 1, 2, 4, and 5 respectively. Product $C$ 
requires parts 3,4 and 5 . The similarity rank of the three products can be calculated by using Equation (1):

$$
S_{i j}=S_{j i}=\frac{\alpha_{i j}}{\beta_{i}} \times \frac{\alpha_{j i}}{\beta_{j}}
$$

where,

$\beta_{i}=$ number of parts in product $i$

$\beta_{j}=$ number of parts in product $j$;

$\alpha_{i j}=$ number of shared parts between product $i$ and $j$;

$\alpha_{j i}=$ number shared parts between product $j$ and $i$;

$S_{i j}=S_{j i}=$ similarity rank of product $i$ and $j$.

The approach to forming a part family is shown in the flowchart in Figure 7. The product's structure first needs to be represented using Green-BOM's structure and attributes. Then, the manufacturer needs to check whether all parts of the products satisfy the Green-BOM's attributes. If not, the parts need to be modified or adjusted to remain environmentally friendly. After that, the eco-friendliness between parts needs to be checked, even though that process can be simultaneously completed while checking the GreenBOM's attributes satisfaction. Then, modularity and similarity rank are calculated before proceeding to form part families.

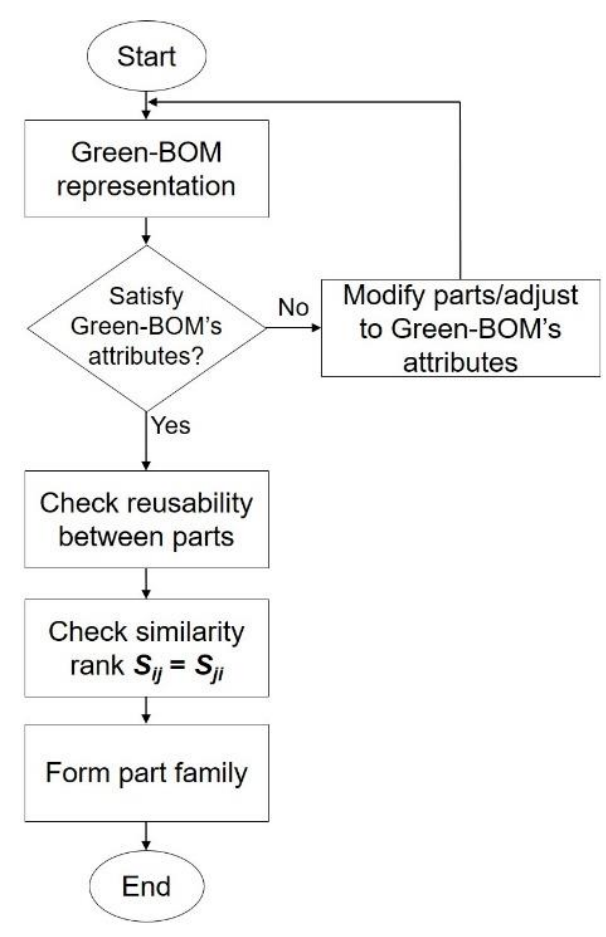

Figure 7. Flowchart of part family formation.

The total summation of the values of all attributes of product $i$ is represented by $T E_{i}$ and the total summation of the values of all attributes of part $n$ used to complete product $i$ is represented by $T E_{n i}$. The eco-friendly rank of the three products can be calculated based on the attribute shown in Table 1 and using Equations (2) and (3) as follows:

$$
\begin{gathered}
E_{i}=\left(T E_{i}+\sum T E_{n i}\right) / \text { total number of } T E \\
E_{i j}=E_{j i}=\left|E_{i}-E_{j}\right|
\end{gathered}
$$

where,

$E_{i}=$ eco-friendly rank of product $i$; 
$E_{j}=$ eco-friendly rank of product $j$;

$E_{i j}=E_{j i}=$ eco-friendly rank difference between product $i$ and $j$;

$T E_{i}=$ total summation attributes value of product $i$;

$T E_{n i}=$ total summation attributes value of part $n$ used to complete product $i$.

Manufacturing a part designed to complete a product usually consists of a number of operations. If a company needs to produce various types of parts, then it will be mandatory to schedule some pieces of equipment to process the same operations. It is more efficient to group similar parts into a family. Part grouping can either be according to the similarities of parts' geometry, fabrication methods, visual inspections, or production flow.

This section discusses the methodology proposed for the grouping part families in RMS by giving weights to the similarity coefficients and by applying the average linkage clustering (ALC) algorithm [37]. Some references also discussed the popular methods of grouping part families [38-41]. The purpose of giving weights is to indicate the value of importance of a predefined objective. In this study, there are two categories of weights considered: modularity/similarity weights and eco-friendly weights. Then, the similarity coefficient for each importance is formulated by using Equation (4):

$$
C_{i j}=W_{m s} S_{i j}+W_{e} E_{i j}
$$

where,

$C_{i j}=C_{j i}=$ similarity between product $i$ and $j$;

$W_{m s}=$ weight for modularity/similarity rank;

$W_{e}=$ weight for eco-friendly rank;

$S_{i j}=$ similarity rank of product $i$ and $j$;

$E_{i j}=$ eco-friendly rank difference between product $i$ and $j$.

\subsection{Development of Smartsheet for Managing Multi-Disciplinary Green-BOM (MDG-BOM)}

The previous chapter discusses how to manage parts in the RMS during the reconfiguration process via a standard Green-BOM. In this section, Green-BOM is improved into MDG-BOM by creating and adding open access to not only the mechanical department but also the software and electric departments. Normally, only the mechanical department handles BOM management in a traditional production environment. However, with the increasing product customization and rapid product change, other departments are involved in the process and need to see the detailed BOM of each product. To avoid errors and misunderstandings, MDG-BOM was developed to handle multi-disciplinary product data and support better collaboration for data tracking between engineers while maintaining sustainability. The structure of the proposed MDG-BOM and its dedicated smart spreadsheet are shown in Figure 8.

MDG-BOM is composed of a Green-BOM with multiple additional attributes of $\mathrm{BOM}$ complexity such as changes, disciplines, $\mathrm{CAD}$, and product lifecycle, which allow the normal Green-BOM to achieve multi-disciplinary capabilities. MDG-BOM has the purpose of maintaining sustainability while solving the Reconfiguration Planning Problem (RPP) in RMS. Maintaining sustainability in RMS is possible because of the application of Green-BOM, which allows RMS to control and monitor energy usage and rapidly respond to customer demands. RPP is solved by applying the proposed formula for calculating the similarity/modularity and the eco-friendly rank between parts, developing integrated tools for product data, and configuring management systems, which are parts of MDG-BOM.

The proposed development of MDG-BOM will be in the format of a smart spreadsheet that aims to manage product data, considered as MDG-BOM. The smart spreadsheet was developed using Microsoft Excel, and consisted of Green-BOM and product data, database and data tracking, the company intranet for internal access, and the user interface. 


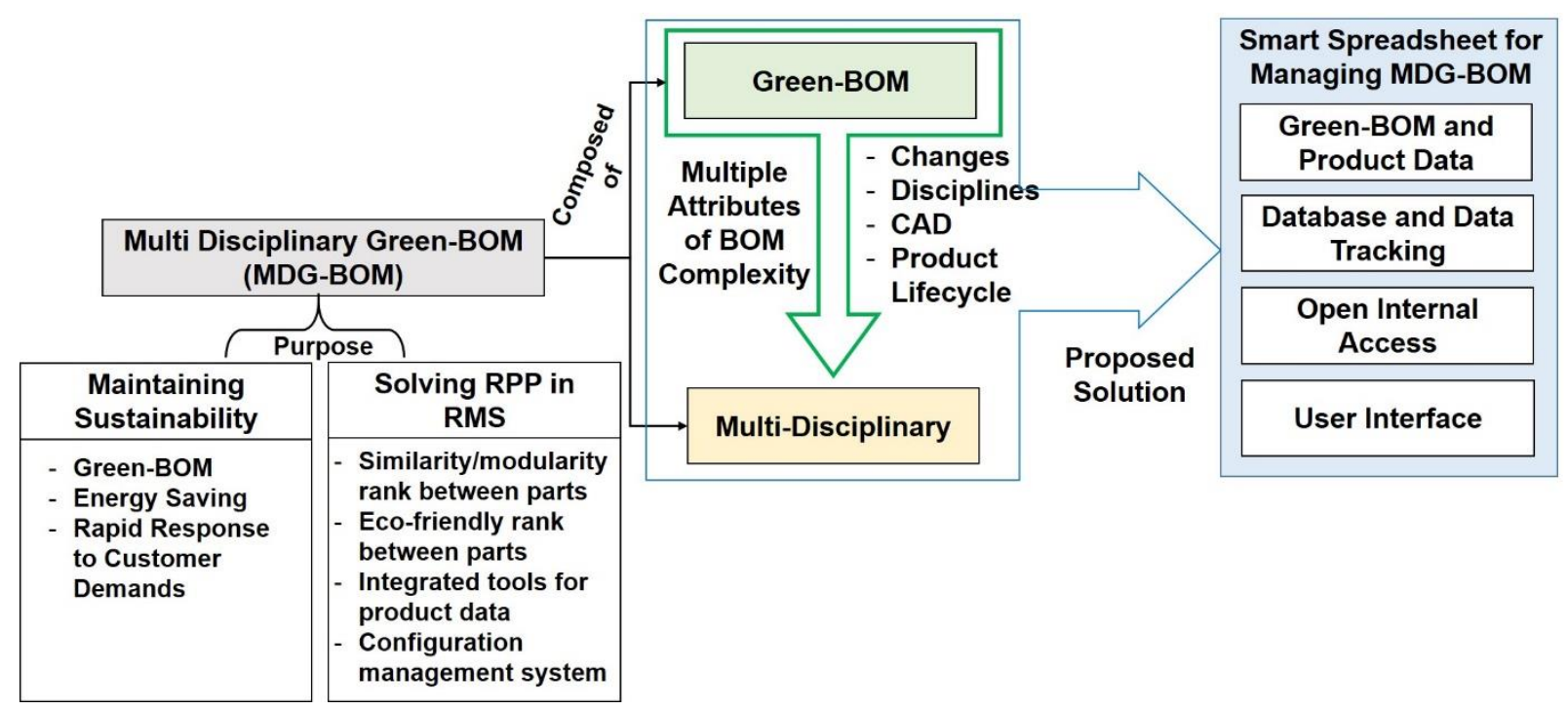

Figure 8. Structure of MDG-BOM and its dedicated smart spreadsheet.

The ability to thrive in such a complex and dynamic environment is only possible with an MDG-BOM approach that helps to consistently measure the effectiveness of data management. MDG-BOM has the following benefits: an efficient configuration management system, connecting multi-disciplinary design to the most comprehensive digital twin, virtual commissioning to simulate, test, and tweak every detail of the machine, ensuring compliance, improving quality, and accelerating development with multi-view BOM. Keeping track of the amount of information that comes with today's machinery is a significant challenge. Information needs to be configured in a way that allows the company to deliver smart and connected machines.

\section{Case Study}

For the case study, a product, referred to as cooling fans in a car, is used for exemplary purpose. Cooling fans are one of the important parts that produce and pull the cooling air through the radiator of the car. The purpose of cooling fans is to avoid overheating the car engine. As seen in Figures 9 and 10, cooling fans can be distinguished into Types 1 and 2, and the BOM of each type is shown.

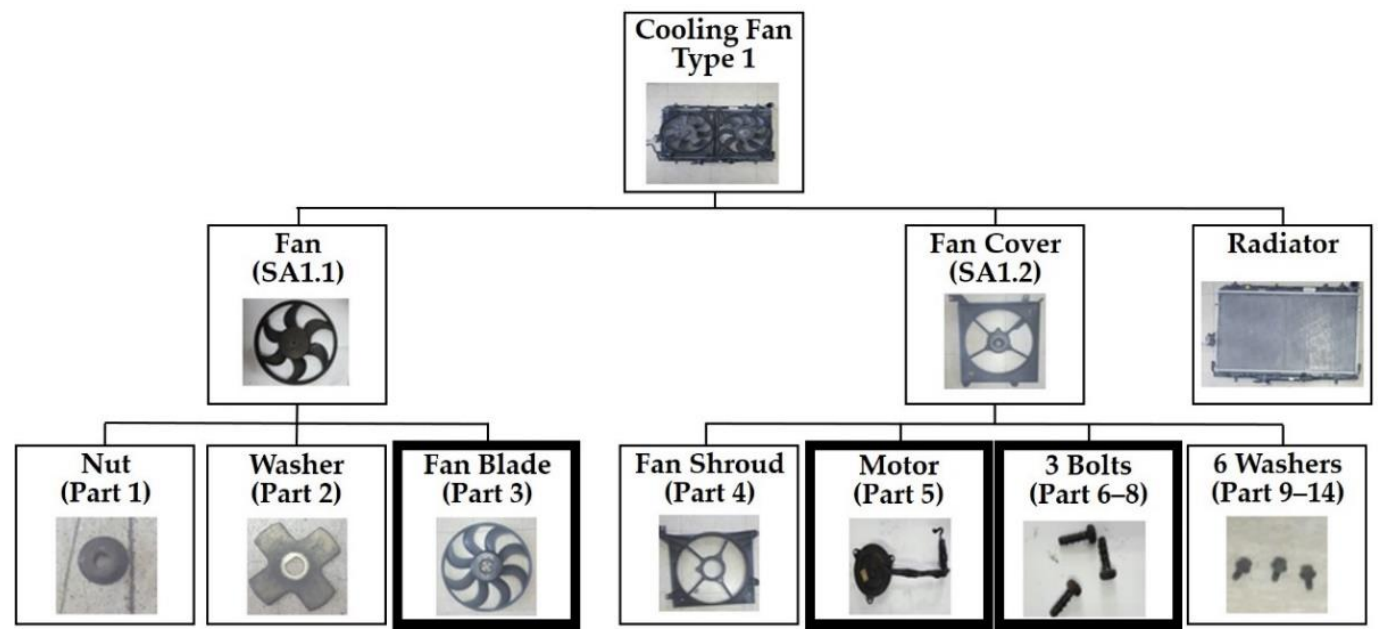

Level 0

Figure 9. Normal BOM of Cooling Fan Type 1. 


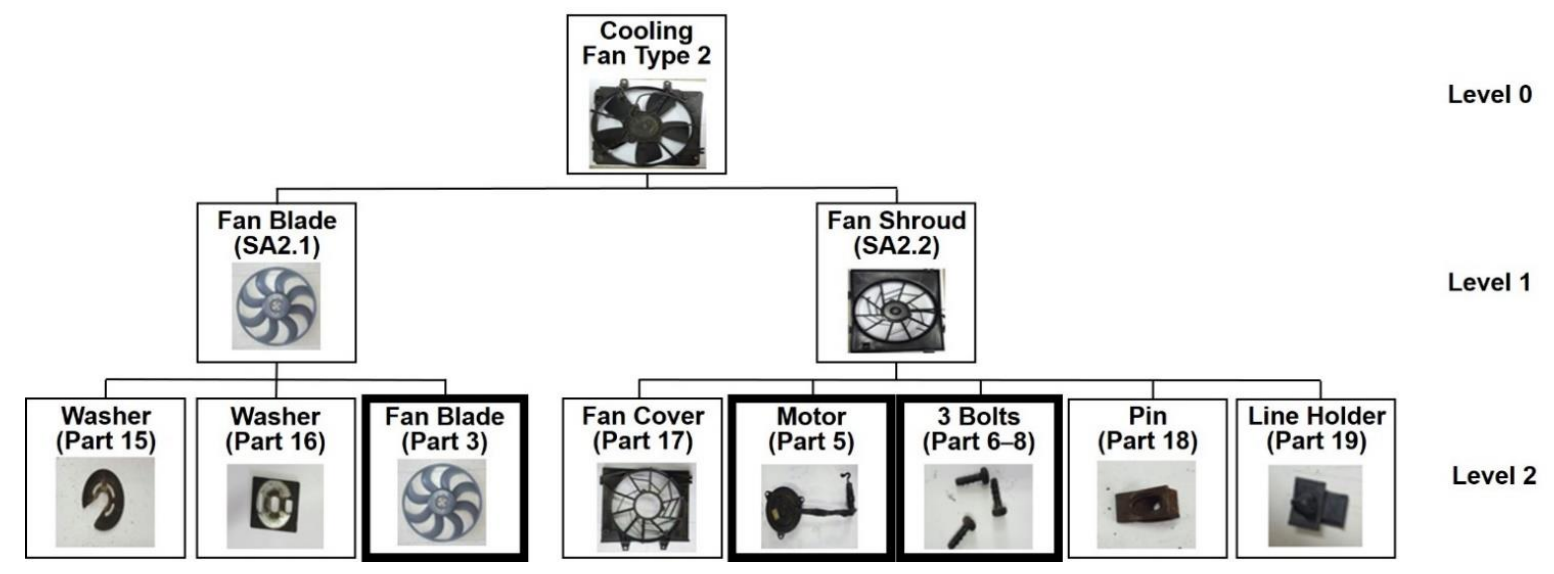

Figure 10. Normal BOM of Cooling Fan Type 2.

The parts in a thicker box in Figures 9 and 10 show the similarity between Types 1 and 2 . As can be seen, parts 3,5 and 6-8 are used in both cooling fan types. Therefore, the numbering of parts starts from part 15 in the Type $2 \mathrm{BOM}$. This method is to help with differentiating parts during the calculation of modularity/similarity rank. The naming of each part is justified by referring to Figures 9 and 10. Except for the parts in thicker boxes, the parts differ from each other, even though the naming is same. This is especially true for the washer. As shown in Figure 7, product structures of Types 1 and 2 are to be transformed to the Green-BOM form. The relevant Green-BOM attributes of each part should be determined by referring to Table 1 . Since not all attributes of Green-BOM are usually available in the real factory floor area, it is necessary to justify the Green-BOM representation. Therefore, the modified factor from Green-BOM that will be taken into consideration is shown in Figure 11, demonstrating the difference between the original and modified Green-BOM components. Finally, Type 1 and Type 2 are transformed to Green-BOM format, which are shown in Figures 12 and 13, respectively.

\begin{tabular}{|l|l|l|l|}
\hline \hline $\begin{array}{l}\text { Part ID } \\
\text { Part Name - No of Item }\end{array}$ & $\begin{array}{l}\text { Name of } \\
\text { Regulation } \\
\text { and R_pos } \\
\text { PoD }\end{array}$ \\
\hline \multicolumn{2}{|c|}{ E_M / E_C / R_TR } \\
\hline
\end{tabular}

(a) For final product

\begin{tabular}{|c|c|c|c|}
\hline $\begin{array}{l}\text { Part ID } \\
\text { Part Name - No of Item }\end{array}$ & $\begin{array}{l}\text { Sub } \\
\text { Type } \\
\text { PoD }\end{array}$ & $\begin{array}{l}\text { Part ID } \\
\text { Part Name - No of Item }\end{array}$ & PoD \\
\hline \multicolumn{2}{|c|}{ J/F_type /E_M / N_IDs } & \multicolumn{2}{|c|}{ J/F_type / T_M / N_IDs } \\
\hline
\end{tabular}

(b) For sub-assembly

\begin{tabular}{|c|c|c|c|}
\hline $\begin{array}{l}\text { Part ID } \\
\text { Part Name - No of Item }\end{array}$ & $\begin{array}{c}\text { Sub } \\
\text { Type } \\
\text { RoHS+ } \\
\text { VOC }\end{array}$ & $\begin{array}{l}\text { Part ID } \\
\text { Part Name - No of Item }\end{array}$ & $\begin{array}{l}\text { RoHS+ } \\
\text { VOC }\end{array}$ \\
\hline \multicolumn{2}{|c|}{ J/F_type /R_sub / N_IDs } & \multicolumn{2}{|l|}{ R_sub } \\
\hline
\end{tabular}

(c) For part

Figure 11. Original (left) and modified (right) Green-BOM structure. (a) Modified green-BOM for the final product differs from the original one in the bottom part, where we only consider T_M / R_TR. Instead of E_M, which represents the energy consumed while making products, $T \_M$ is used, which represents the time consumed while making products; (b) Modified green-BOM for sub-assembly only removes the Sub Type in the top right part; (c) Modified green-BOM for part removes the Sub Type in the top right part, as well as J/F_type and N_IDs in the bottom part. The name of regulation is assumed to be RoHS. 


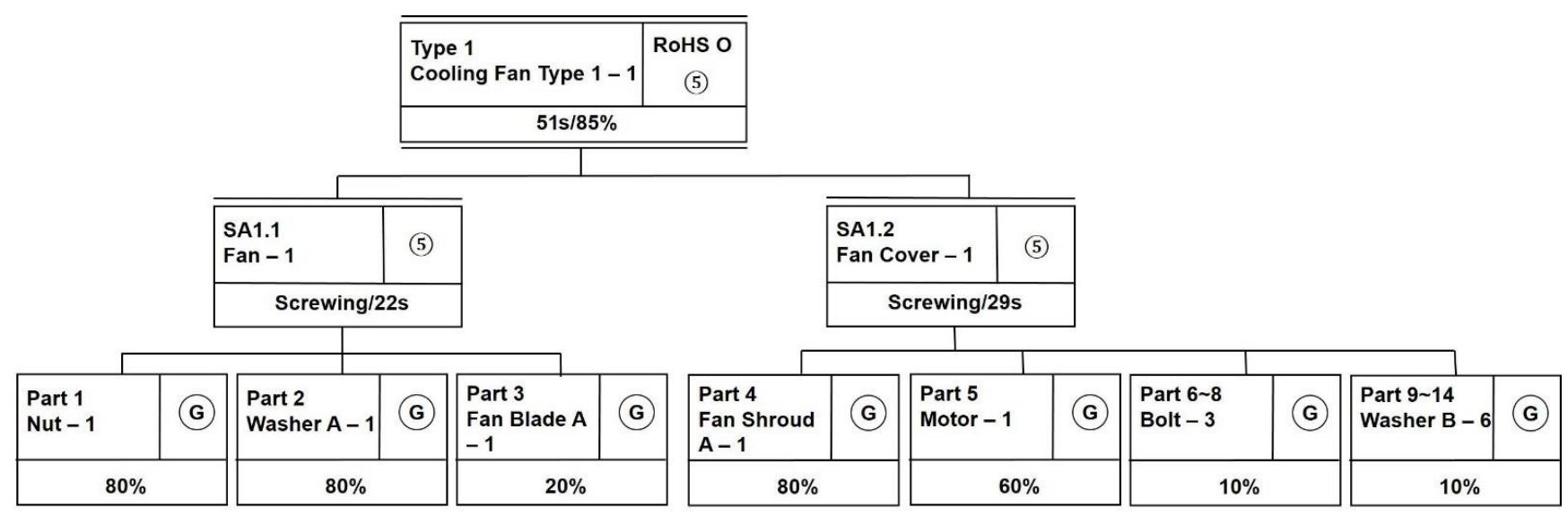

Figure 12. Product structure of Cooling Fan Type 1 in Green-BOM format.

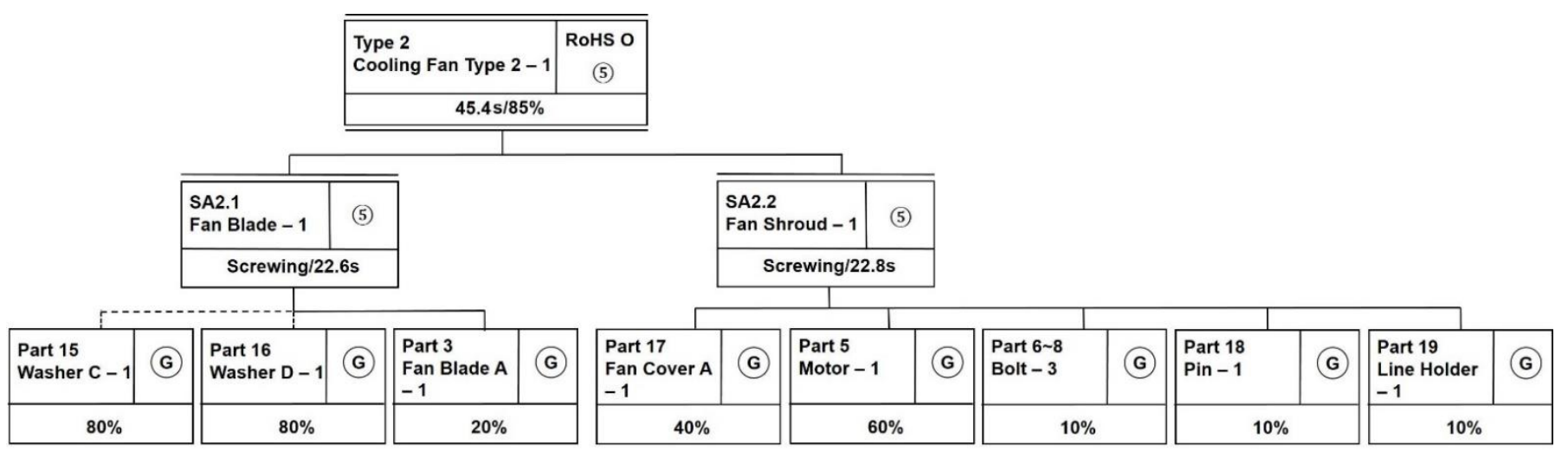

Figure 13. Product structure of Cooling Fan Type 2 in Green-BOM format.

The modularity between Types 1 and 2 is calculated and presented in Table 2 . As shown in Figures 9 and 10, both products use parts 3, 5, 6, 7, and 8 .

Table 2. Table of modularity.

\begin{tabular}{ccc}
\hline Part ID & Type $\mathbf{1}$ & Type 2 \\
\hline 1 & O & - \\
2 & O & - \\
3 & O & O \\
4 & O & - \\
5 & O & O \\
$6-8$ & O & O \\
$9-14$ & O & - \\
15 & - & O \\
16 & - & O \\
17 & - & O \\
18 & - & O \\
19 & - & O \\
\hline
\end{tabular}

Then, the similarity rank between both products is calculated using Equation (1), as follows:

$$
S_{12}=S_{21}=\frac{5}{14} \times \frac{5}{10}=0.17
$$

By using the attributes of the Green-BOM, it is assumed that the following parts and products have their own attribute values as presented in Table 3. By referring to the modification of Green-BOM illustrated in Figure 11, there are a few differences in Green-BOM attributes between products and parts. The $\mathrm{R} \_$sub attribute is not contained in 
the Cooling Fan Type 1 and Type 2, while the R_TR attribute is not contained in any of the parts. Green-BOM attributes that are included in Table 3 are the ones that are available to be accessed from the real factory floor at the moment. Such attribute values can also represent the energy consumption of making a product. The higher possibility of parts/substances reuse and disassembly a product has, the lower energy consumption a product produces. Therefore, the attributes shown in Table 3 are used to calculate $T E_{i}$.

Table 3. Table of Green-BOM attributes' value.

\begin{tabular}{cccccc}
\hline Product and Part & $\begin{array}{c}\text { Reuse Possibility } \\
\text { of Parts }\end{array}$ & $\begin{array}{c}\text { Possibility of } \\
\text { Disassembly }\end{array}$ & $\begin{array}{c}\text { Percentage of Reusable } \\
\text { Substance in an Item }\end{array}$ & $\begin{array}{c}\text { Percentage of Reusable } \\
\text { Parts in a Product }\end{array}$ & $\begin{array}{c}\text { Total } \\
\left(T_{\boldsymbol{i}}\right)\end{array}$ \\
\hline Type 1 & 1 & 5 & 0.75 & 6.75 \\
Type 2 & 1 & 5 & 0.85 & 6.85 \\
\hline $1,2,4,15,16$ & & 5 & & 0.8 & 5.2 \\
3 & & 5 & 0.6 & 5.2 \\
5 & 5 & & 0.1 & 5.6 \\
$6-14,18,19$ & 5 & & 0.4 & 5.1 \\
17 & & 5 & & \\
\hline
\end{tabular}

Based on the attributes given in Table 3 and using Equations (2) and (3), the ecofriendly rank of the two products can be calculated as follows:

$$
\begin{gathered}
E_{1}=\left(T E_{1}+\sum T E_{141}\right) / 15=(6.75+74.1) / 15=5.39 \\
E_{2}=\left(T E_{2}+\sum T E_{102}\right) / 11=(6.85+73.1) / 11=7.27 \\
E_{12}=E_{21}=\left|E_{1}-E_{2}\right| \\
E_{12}=E_{21}=|5.39-7.27|=1.88
\end{gathered}
$$

By using Equation (4), the similarity coefficients of Types 1 and 2, $C_{12}$, are calculated as shown below. As mentioned before, weights are divided into the modularity/similarity weight and the eco-friendly weight. The weights given for the modularity/similarity $W_{m s}$ and the eco-friendly $W_{e}$ are 0.55 and 0.45 , respectively, while the values of the similarity rank $S_{12}$ and the eco-friendly rank of both products $E_{12}$ are 0.17 and 1.88 , respectively.

$$
C_{12}=W_{m s} S_{12}+W_{e} E_{12}=0.55 \times 0.17+0.45 \times 1.88=0.0935+0.846=0.079101
$$

The value of the weights is subjective and can be adjusted by any manufacturer or company depending on their requirements. In the weights given above, almost half the value of both weights is assumed. Therefore, the final value of the similarity coefficient was small. However, we can see from the similarity rank (i.e., 0.17) and the eco-friendly rank (i.e., 1.88) that the similarities of Cooling Fan Type 1 and Type 2 are in terms of the eco-friendly functions. This is caused by the total number of shared parts between two products. There are only five parts, which is a relatively small number.

The next step is to transform the Green-BOM format into MDG-BOM by using the templates of a smart spreadsheet. The templates used in this study are shown in Figure 14, representing Cooling Fan Type 1, and Figure 15 representing Cooling Fan Type 2. 
MULTI-LEVEL BILL OF MATERIALS TEMPLATE

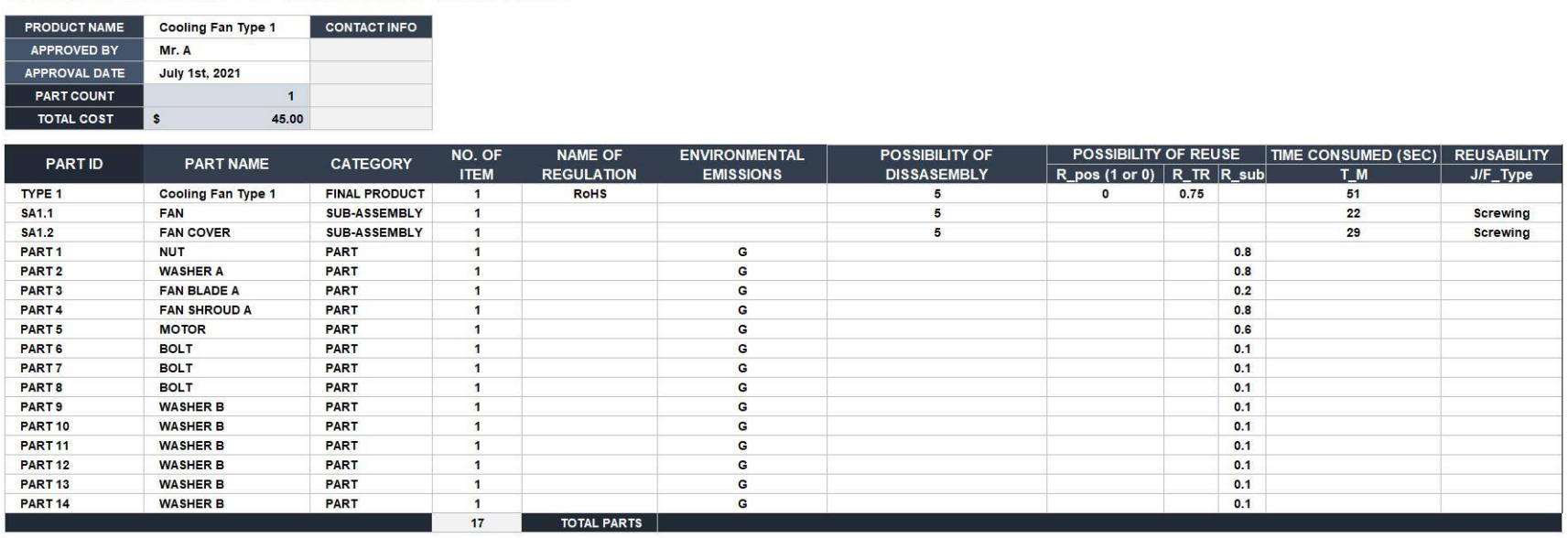

Figure 14. Smart spreadsheet of Cooling Fan Type 1.

MULTI-LEVEL BILL OF MATERIALS TEMPLATE

\begin{tabular}{|c|c|c|c|c|c|c|c|c|c|c|c|}
\hline $\begin{array}{l}\text { PRODUCT NAME } \\
\text { APPROVED BY }\end{array}$ & Cooling Fan Type 2 & CONTACT INFO & & & & & & & & & \\
\hline APPROVAL DATE & July 1st, 2021 & & & & & & & & & & \\
\hline PART COUNT & & & & & & & & & & & \\
\hline TOTAL COST & & & & & & & & & & & \\
\hline PARTID & PARTNAME & CATECORY & No. OF & NAME OF & ENVIRONMENTAL & POSSIBILITY OF & POSSIBILITY & YOF REU & & TIME CONSUMED (SEC & \\
\hline PARIID & PAKI IAMIE & CAIEEUKY & ITEM & REGULATION & EMISSIONS & DISSASEMBLY & R_pos (1 or 0) & $R_{-}$TR & R_sub & $T_{\text {_M }}$ & JIF_Type \\
\hline $\begin{array}{l}\text { TYPE 2 } \\
\text { SA21 }\end{array}$ & Cooling Fan Type 2 & $\begin{array}{l}\text { FINAL PRODUCT } \\
\text { S }\end{array}$ & 1 & & & 5 & & & & 45.4 & \\
\hline $\begin{array}{l}\text { SAA.1 } \\
\text { SA2.2 }\end{array}$ & $\begin{array}{l}\text { FAN BLADE } \\
\text { FN SHROUD }\end{array}$ & $\begin{array}{l}\text { SUB-ASSEMBLY } \\
\text { SUBASEMBYY }\end{array}$ & 1 & & & 5 & & & & 22.6 & Screwing \\
\hline $\begin{array}{l}\text { SAR.2 } \\
\text { PART } 15\end{array}$ & WASHER C & $\begin{array}{l}\text { SUBRT } \\
\text { PAREMBLT }\end{array}$ & 1 & & $G^{6}$ & & & & 0.8 & & \\
\hline PART 16 & WASHER D & PART & 1 & & G & & & & 0.8 & & \\
\hline PART 3 & FAN BLADE A & PART & 1 & & $G$ & & & & 0.2 & & \\
\hline & FAN COVER A & PART & 1 & & G & & & & 0.4 & & \\
\hline PART 5 & MOTOR & PART & 1 & & $\mathrm{G}$ & & & & 0.6 & & \\
\hline PART 6 & BOLT & PART & 1 & & G & & & & 0.1 & & \\
\hline PART T & BOLT & PART & 1 & & G & & & & 0.1 & & \\
\hline PART 8 & BOLT & PART & 1 & & G & & & & 0.1 & & \\
\hline PART 18 & PIN & PART & 1 & & $\mathrm{G}$ & & & & 0.1 & & \\
\hline PART 19 & LINE HOLDER & PART & 1 & & $\mathrm{G}$ & & & & 0.1 & & \\
\hline
\end{tabular}

Figure 15. Smart spreadsheet of Cooling Fan Type 2.

\section{Discussion}

The proposed methodology incorporates problem solving of the reconfiguration planning in RMS and the importance of sustainability, the application of the Green-BOM and multi-disciplinary concepts altogether in order to maintain sustainability in RMS. First of all, changeability in RMS caused by rapidly changing market demands and product variations appears as a chance of sustainability to be used as one of competitive solutions. Especially in RMS, such reconfiguration planning problem requires quite a lot of energy consumption when the reconfiguration process happens. Such planning activities must be conducted continuously, and product life cycles must be highly considered during reconfiguration planning, which includes three pillars of sustainability: environment, society, and economy. Sustainability and reconfiguration planning problem in RMS are strongly related to each other.

In order to support the integration of sustainability into solving reconfiguration planning problems in RMS, the Green-BOM is introduced and applied. Manufacturers adopt the concept of Green-BOM to stay focused on and aware of the negative impacts to environment. To produce eco-friendly products, managing product environmental data is crucial. However, a standard Green-BOM is not enough for such an environment. For a complex RMS environment, the multi-disciplinary concept is added into the old Green-BOM format, where it is referred to as Multi-Disciplinary Green-BOM (MDG-BOM).

MDG-BOM combines the concept of multi-disciplinary and an old format of GreenBOM. Multi-disciplinary means multiple combining or involving more than one discipline or field of study, where it applies in the real production environment because there are 
many departments involved in managing BOM. Therefore, MDG-BOM means a BOM that is able to be managed by more than one department in a company and a BOM that allows for neutral and flexible collaborative data management from multiple personnel. The development of such a BOM is suitable for an RMS environment where the system performs reconfiguration processes and mass customization constantly.

The management of BOM is crucial in such a manufacturing environment, especially for the reconfiguration process in RMS. BOMs are often handled by more than one department, which creates many errors and misunderstandings between departments, suppliers, and OEMs. There is a requirement for an integrated tool, and as of today, the available tools are not adequately efficient for managing one or multiple BOMs that contain mechanical, electronic, and software pieces. There is a necessity to create tools that are capable of managing multi-disciplinary product data and that are able to facilitate better collaboration and integrated data/information tracking between departments.

The complexity of the reconfiguration, product variation, and development processes requires tools that are capable of managing multi-disciplinary $\mathrm{BOM} /$ product data and providing a better collaboration support for data/information tracking while maintaining sustainability. Therefore, an improved Green-BOM concept, referred to as MDG-BOM, is proposed with an additional multi-disciplinary feature to minimize emissions and hazardous materials during product development, as well as to manage product information across multiple disciplines during the reconfiguration process. A smart spreadsheet for managing MDG-BOM was developed to allow multiple departments to integrate multiple sources of CAD design data and monitor/track changes throughout each step of the process.

This paper introduces step-by-step process for grouping part families in RMS, starting with transforming a normal BOM of a product to a Green-BOM format, where each part's Green-BOM attributes are investigated. However, a Green-BOM format that is used in this manuscript is modified based on the available Green-BOM's attributes value that are accessible at the moment. After that, the reusability and similarity rank between parts are calculated in order to form a part family. Then, the eco-friendly rank of the products can be calculated based on the available Green-BOM attributes. The weights are given into each modularity/similarity rank and eco-friendly rank in order to examine the goal of companies, whether they focus more on eco-friendliness or modularity/similarity. It is completely subjective and can be modified any time by the company based on their organization's goal. The higher the weights given to one rank, the higher the priority of that rank.

For the purpose of user interface, a smart spreadsheet of MDG-BOM was created in Microsoft Excel, as can be seen in Figures 14 and 15 representing MDG-BOM Format of Cooling Fan Type 1 and Cooling Fan Type 2, respectively. The template consists of product name, approving operator, approved date, part count, and total cost on the top area. In the bottom area, there are columns representing standard part attributes, such as Part ID, Part Name, Category of levels in BOM, number of items, and Green-BOM attributes, such as the name of the regulation, environmental emissions, possibility of disassembly, possibility of reuse, time consumed, and reusability. This spreadsheet is created in order to any operator in many departments easily monitor and access information.

\section{Conclusions}

This study presented an approach for grouping parts into families in RMS, which is a critical issue during the process of RMS reconfiguration, while also considering the importance of sustainability by adopting Green-BOM in the process of listing the products and parts to be produced. The benefit of RMS implementation on the factory floor is its capability to reconfigure its system to produce a customized product, meaning that it is crucial to form part families. This paper firstly introduces the reconfiguration planning problem in RMS. Therefore, a systematic approach to solve reconfiguration planning is introduced and an analysis of RMS and environmental perspectives is presented. The 
framework of reconfiguration planning problem is developed, which shows RMS environment, options, components and documents. From there, documents that are represented by Green-BOM are further investigated by transforming the normal BOM into the Green-BOM format at the starting point of production process. Green-BOM's attributes are described and included when listing the part and products to increment sustainability value in RMS. In order to group part families, the modularity/similarity and eco-friendly ranks are calculated by using weighting methods. The purpose of grouping part families is to achieve more efficient production since RMS is mostly about customized and complex products.

In order to cope with managing multi-disciplinary data from across multiple disciplines during the reconfiguration process, MDG-BOM was also developed by improving Green-BOM with the additional multiple attributes of BOM complexity. This study further enables multiple departments in a company to monitor and maintain product data. Smart MDG-BOM spreadsheets have the following benefits: an efficient configuration management system, connecting multi-disciplinary design to the most comprehensive digital twin, virtual commissioning to simulate, test, and tweak every detail of the machine, ensuring compliance, improving quality, and accelerating development with multi-view BOM. Keeping track of the amount of information that comes with today's machinery is a significant challenge and information needs to be configured in a way that allows the company to deliver smart and connected machines.

For future research, more Green-BOM attributes will be included in the calculation of energy consumption of making a product, such as M_toxic, M_Guide, Density of VOCs, R_Usage, R_Reused, E_M, and E_C that are available in the original form of the GreenBOM. Furthermore, a more thorough and proper formulation of energy consumption is to be applied. Structural modeling of MDG-BOM is to be developed in order to provide better supporting tools during reconfiguration processes in RMS, where communication errors can be minimized. A database and a User Interface are also to be developed for easier data inputting, tracking and monitoring that is accessible to all relevant disciplines. In the future, the automation of transforming data and values in Green-BOM into smart spreadsheets will likely to be developed.

Author Contributions: Conceptualization, K.A.K. and K.R.; methodology, K.A.K.; software, K.A.K.; validation, K.A.K. and K.R.; formal analysis, K.A.K.; investigation, K.R.; resources, K.A.K. and K.R.; data curation, K.A.K.; writing-original draft preparation, K.A.K.; writing-review and editing, K.A.K. and K.R.; visualization, K.A.K.; supervision, K.R.; project administration, K.R.; funding acquisition, K.R. All authors have read and agreed to the published version of the manuscript.

Funding: This research received no external funding.

Institutional Review Board Statement: Not applicable.

Informed Consent Statement: Not applicable.

Data Availability Statement: Not applicable.

Acknowledgments: This research was supported by the MSIT (Ministry of Science and ICT), Korea, under the Grand Information Technology Research Center support program (IITP-2021-2020-0-01791) supervised by the IITP (Institute for Information \& communications Technology Planning \& Evaluation).

Conflicts of Interest: The authors declare no conflict of interest.

\section{References}

1. Koren, Y. The Global Manufacturing Revolution Product-Process-Business Integration and Reconfigurable Systems; John Wiley \& Sons: Hoboken, NJ, USA, 2010.

2. Koren, Y.; Ulsoy, A.G. Vision, Principles and Impact of Reconfigurable Manufacturing Systems. Int. J. Powertrains 2002, 5, 14-21.

3. Maier-Speredelozzi, V.; Koren, Y.; Hu, S.J. Convertibility Measures for Manufacturing Systems. CIRP Ann. Manuf. Technol. 2003, 1, 367-371. [CrossRef]

4. Hauschild, M.; Jeswiet, J.; Alting, L. From Life Cycle Assessment to Sustainable Production: Status and Perspectives. CIRP Ann. Manuf. Technol. 2005, 4, 1-21. [CrossRef] 
5. Ryu, K. Green Product and Production Information Management in The Fractal Manufacturing Systems. In Proceedings of the 21st International Conference on Production Research (ICPR21), Stuttgart, Germany, 31 July-4 August 2011; pp. 1-8.

6. Leahu, S. Sustainable Manufacturing-An Overview for Manufacturing Engineers, Sustainable Manufacturing Consulting. Available online: http:/ / sustainablemanufacturing.biz/ (accessed on 30 November 2017).

7. Brent, A.C.; Labuschagne, C. Sustainable Life Cycle Management: Indicators to Assess the Sustainability of Engineering Projects and Technologies. In Proceedings of the 2004 IEEE International Engineering Management Conference, Singapore, 18-21 October 2004; pp. 99-103.

8. Löffler, C.; Westkämper, E.; Unger, K. Changeability in Structure Planning of Automotive Manufacturing. Procedia CIRP 2012, 3 , 167-172. [CrossRef]

9. Karl, F.; Reinhart, G.; Zäh, M.F. Strategic Planning of Reconfigurations on Manufacturing Resources. Procedia CIRP 2012, 3, 608-613. [CrossRef]

10. Wiendahl, H.P.; El Maraghy, H.A.; Zäh, M.F.; Wiendahl, H.H.; Duffie, N.; Kolakowski, M. Changeable Manufacturing-Classification, Design, Operation. Ann. CIRP 2007, 56, 783-809. [CrossRef]

11. Azab, A.; El Maraghy, H.A.; Nyhuis, P.; Pachow-Frauenhofer, J.; Schmidt, M. Mechanics of Change: A Framework to Reconfigure Manufacturing Systems. CIRP J. Manuf. Sci. Technol. 2013, 6, 110-119. [CrossRef]

12. Yoram, K.; Moshe, S. Technical Paper: Design of Reconfigurable Manufacturing Systems. J. Manuf. Syst. 2010, $29,130-141$.

13. Mehrabi, M.; Ulsoy, A.G.; Koren, Y. Trends and Perspectives in Flexible and Reconfigurable Manufacturing Systems. J. Intell. Manuf. 2002, 13, 135-146. [CrossRef]

14. Koren, Y. General RMS Characteristics. Comparison with Dedicated and Flexible System. In Reconfigurable Manufacturing Systems and Transformable Factories; Dashchenko, A.I., Ed.; Springer: Berlin/Heidelberg, Germany, 2006; pp. $27-46$.

15. Koren, Y.; Heisel, U.; Jovane, F.; Moriwaki, T.; Pritschow, G.; Ulsoy, G.; Van Brussel, H. Reconfigurable Manufacturing Systems. CIRP Ann. Manuf. Technol. 1998, 48, 527-540. [CrossRef]

16. Heisel, U.; Meitzner, M. RMS-Opportunities and Challenges. In Proceedings of the CIRP 1st International Conference on Reconfigurable Manufacturing, Ann Arbor, MI, USA, 20-21 August 2001.

17. Mastura, M.T.; Sapuan, S.M.; Mansor, M.R.; Nuraini, A.A. Materials Selection of Thermoplastic Matrices for 'Green' Natural Fibre Composites for Automotive Anti-Roll Bar with Particular Emphasis on the Environment. Int. J. Precis. Eng. Manuf. Green Technol. 2018, 5, 111-119. [CrossRef]

18. Kim, J.; Shim, B.S.; Kim, H.S.; Lee, Y.; Min, S.; Jang, D.; Abas, Z.; Kim, J. Review of Nanocellulose for Sustainable Future Materials. Int. J. Precis. Eng. Manuf. Green Technol. 2015, 2, 197-213. [CrossRef]

19. Wang, W.; Tian, G.; Zhang, T.; Jabarullah, N.H.; Li, F.; Fard, A.M.; Wang, D.; Li, Z. Scheme Selection of Design for Dissassembly (DFD) Based on Sustainability: A Novel Hybrid of Interval 2-tuple Linguistic Intuitionistic Fuzzy Numbers and Regret Theory. J. Clean. Prod. 2021, 281, 124724. [CrossRef]

20. Tian, G.; Zhang, H.; Feng, Y.; Wang, D.; Peng, Y.; Jia, H. Green Decoration Materials Selection under Interior Environment Characteristics: A Grey-Correlation Based Hybrid MCDM Method. Renew. Sustain. Energy Rev. 2018, 81, 682-692. [CrossRef]

21. Tian, G.; Zhang, H.; Feng, Y.; Jia, H.; Zhang, C.; Jiang, Z.; Li, Z.; Li, P. Operation Patterns Analysis of Automotive Components Remanufacturing Industry Development in China. J. Clean. Prod. 2017, 164, 1363-1375. [CrossRef]

22. Xing, K.; Qian, W.; Zaman, A.U. Development of a Cloud-Based Platform for Footprint Assessment in Green Supply Chain Management. J. Clean. Prod. 2016, 139, 191-203. [CrossRef]

23. Qiang, F.; Zhong, W.; Du, W. Fundamental Theories and Key Technologies for Smart and Optimal Manufacturing in the Process Industry. Engineering 2017, 3, 154-160. [CrossRef]

24. Yadav, G.; Luthra, S.; Jakhar, S.K.; Mangla, S.K.; Rai, D.P. A Framework to Overcome Sustainable Supply Chain Challenges Through Solution Measures of Industry 4.0 and Circular Economy: An Automotive Case. J. Clean. Prod. 2020, $254,120112$. [CrossRef]

25. Khan, I.S.; Ahmad, M.O.; Majava, J. Industry 4.0 and Sustainable Development: A Systematic Mapping of Triple Bottom Line, Circular Economy and Sustainable Business Models Perspectives. J. Clean. Prod. 2021, 297, 126655. [CrossRef]

26. Beltrami, M.; Orzes, G.; Sarkis, J.; Sartor, M. Industry 4.0 and Sustainability: Towards Conceptualization and Theory. J. Clean. Prod. 2021, 312, 127733. [CrossRef]

27. Bai, C.; Dallasega, P.; Orzes, G.; Sarkis, J. Industry 4.0 Technologies Assessment: A Sustainability Perspective. Int. J. Prod. Econ. 2020, 229, 107776. [CrossRef]

28. Beier, G.; Ullrich, A.; Niehoff, S.; Reibig, M.; Habich, M. Industry 4.0: How It Is Defined from A Sociotechnical Perspective and How Much Sustainability It Includes-A Literature Review. J. Clean. Prod. 2020, 259, 120856. [CrossRef]

29. Dantas, T.E.T.; Souza, E.D.; Destro, I.R.; Hammes, G.L.; Rodriguez, C.M.T.; Soares, S.R. How the Combination of Circular Economy and Industry 4.0 Can Contribute towards Achieving the Sustainable Development Goals. Sustain. Prod. Consum. 2021, 26, 213-227. [CrossRef]

30. Makris, S.; Alexopoulos, K. AutomationML server-A Prototype Data Management System for Multi Disciplinary Production Engineering. Procedia CIRP 2012, 2, 22-27. [CrossRef]

31. Wang, P.; Tian, H.; Zhu, H.; Cai, G. Multi-disciplinary Design Optimization with Fuzzy Uncertainties and Its Application in Hybrid Rocket Motor Powered Launch Vehicle. Chin. J. Aeronaut. 2020, 33, 1454-1467. [CrossRef] 
32. Zhang, X.; Huang, H.-Z. Sequential Optimization and Reliability Assessment for Multidisciplinary Design Optimization under Aleatory and Epistemic Uncertainties. Struct. Multidiscip. Optim. 2009, 40, 165-175. [CrossRef]

33. Gershenson, J.K.; Prasad, G.J.; Zhang, Y. Product Modularity: Definitions and Benefits. J. Eng. Des. Technol. 2003, 14, 295-313. [CrossRef]

34. Kusiak, A. The Generalized Group Technology Concept. Int. J. Prod. Res. 1987, 25, 561-569. [CrossRef]

35. He, D.; Babayan, A. Scheduling Manufacturing Systems for Delayed Product Differentiation in Agile Manufacturing. Int. J. Prod. Res. 2002, 40, 2461-2481. [CrossRef]

36. Tu, Q.; Vonderembse, A.; Ragu-Nathan, T.S.; Ragu-Nathan, B. Measuring Modularity-Based Manufacturing Practices and Their Impact on Mass Customization Capability: A Customer-Driven Perspective. Decis. Sci. 2004, 35, 147-168. [CrossRef]

37. Dasari, R.V.; Moon, Y.B. Analysis of Part Family for Group Technology Applications Using Decision Trees. Int. J. Adv. Manuf. Technol. 1997, 13, 116-124. [CrossRef]

38. Srinivasan, G.; Narendran, T.T.; Mahadevan, B. An Assignment Model for the Part-Family Problem in Group Technology. Int. J. Prod. Res. 1987, 28, 145-152. [CrossRef]

39. Rajamani, S.; Rajamani, D. Cellular Manufacturing Systems: Design, Planning, and Control; Chapman \& Hall: Suffolk, UK, 1996.

40. Hajkowicz, S.A.; McDonald, G.T.; Smith, P.N. An Evaluation of Multiple Objective Decision Support Weighting Techniques in Natural Resource Management. J. Environ. Plan. Manag. 2000, 43, 505-518. [CrossRef]

41. Galan, R.; Racero, J.; Eguia, I.; Garcia, J.M. A Systematic Approach for Part Family formation in Reconfigurable Manufacturing Systems. Adv. Robot. 1997, 23, 489-502. 